Hammouda et al., Afr J Tradit Complement Altern Med. (2013) 11(2):277-279

http://dx.doi.org/10.4314/ajtcam.v11i2.8

\title{
EVALUATION OF THE ESSENTIAL OIL OF FOENICULUM VULGARE MILL (FENNEL) FRUITS EXTRACTED BY THREE DIFFERENT EXTRACTION METHODS BY GC/MS
}

\author{
Faiza M. Hammouda ${ }^{1 *}$, Mahmoud A. Saleh ${ }^{2}$, Nahla S. Abdel-Azim ${ }^{1}$, Khaled A. Shams ${ }^{1}$, Shams I. Ismail ${ }^{1}$, \\ Abdelaaty A. Shahat ${ }^{1}$ and Ibrahim A. Saleh ${ }^{1}$
}

\author{
${ }^{1}$ Department of Phytochemistry, National Research Centre (NRC), 12622 Dokki, Cairo, Egypt. \\ ${ }^{2}$ Department of Chemistry, Texas Southern University, 3100 Cleburne Ave, Houston, TX 77004, USA. \\ *E-mail: fmhammouda@yahoomail.com
}

\begin{abstract}
Background: Hydrodistillation (HD) and steam-distillation, or solvent extraction methods of essential oils have some disadvantages like thermal decomposition of extracts, its contamination with solvent or solvent residues and the pollution of residual vegetal material with solvent which can be also an environmental problem. Thus, new green techniques, such as supercritical fluid extraction and microwave assisted techniques, are potential solutions to overcome these disadvantages.

Materials and Methods: The aim of this study was to evaluate the essential oil of Foeniculum vulgare subsp. Piperitum fruits extracted by three different extraction methods viz. Supercritical fluid extraction (SFE) using $\mathrm{CO}_{2}$, microwave-assisted extraction (MAE) and hydro-distillation (HD) using gas chromatography-mass spectrometry (GC/MS).

Results: The results revealed that both MAE and SFE enhanced the extraction efficiency of the interested components. MAE gave the highest yield of oil as well as higher percentage of Fenchone (28\%), whereas SFE gave the highest percentage of anethol (72\%).

Conclusion: Microwave-assisted extraction (MAE) and supercritical fluid extraction (SFE) not only enhanced the essential oil extraction but also saved time, reduced the solvents use and produced, ecologically, green technologies.
\end{abstract}

Keywords: Foeniculum vulgare subsp. Piperitum, microwave-assisted extraction (MAE), Supercritical fluid extraction (SFE), Essential Oils, Anethol, Fenchone, Limonene, Pinene, GC/MS.

\section{Introduction}

Fennel (Foeniculum vulgare Mill.), family Apiaceae (Umbelliferae) is an annual, biennial or perennial aromatic herb. It is native to southern Europe and the Mediterranean area (Pasrija Anubhuti, et al., 2011; Abdelaaty et al., 2012a).

Fennel is commercially cultivated in Egypt and grows wild in many areas of the Egyptian desert. It is represented in Egypt by two fennel types: sweet fennel, Foeniculum vulgare Mill. subsp. vulgare, and bitter fennel, Foeniculum vulgare subsp. Piperitum (Boulos, L. 2005). It is used as a spice and also as an important ingredient in various folklore medicines throughout the world. Several fennel parts are edible (bulbs, leaves, stalks, and fruits). Mature fruits (commonly known as seeds) and essential oil of fennel are used as flavoring agents in food products for appetizing, as digestive aid, liqueurs, bread, cheese and an ingredient of cosmetics and pharmaceutical products. Moreover fennel infusions are the classical decoction for nursing babies to prevent flatulence and colic spasms [Abdelaaty et al., 2012b; Mimica-Dukić et al., 2003; Perry et al., 2011; Bruyas-Bertholon et al., 2012]. The plant has been investigated extensively for several medicinal and therapeutic activities and has been reported for possessing carminative, antioxidant, antibacterial, antifungal and mosquito repellent properties [WHO, 2005; Damianova et al., 2004].

Fennel volatile oil is a mixture of many different constituents and the main ingredients are: anethole (40 - 70\%), fenchone (1 - 20\%) and estragole (2 - 9\%). (Pasrija Anubhuti et al., 2011; Cosge et al., 2008; Raghavan S., 2006).

In the essential oil of sweet fennel, the fenchone content usually does not exceed 5\%, whereas in the bitter types its content can be as high as $20 \%$. In sweet fennel oil, the anethole content reaches $84-90 \%$, whereas its proportion in bitter fennel is about 61- 70\% (Lawrence, 1994).

Hydrodistillation (HD) and steam-distillation, or solvent extraction methods of essential oils have some disadvantages like thermal decomposition of extracts, its contamination with solvent or solvent residues. The pollution of residual vegetal material with solvent can be also an environmental problem (Árpád et al., 2011).

It is significant to develop more efficient methods for, standardization and quantification the extraction of the essential oil. Thus, new green techniques, such as supercritical fluid extraction, ultrasound and microwave assisted techniques, are potential solutions for energy consumption reduction (Lucchesi et al., 2004; Milojević et al., 2008) and/or for solving the environmental problems of residues (Lucchesi et al., 2004). Nowadays, microwave-assisted hydrodistillation (MWHD) became a widely used method for obtaining the essential oils from different medicinal plants due to its advantages (e.g. more effective heating, shortened extraction time) in comparison with the classical HD. The heating process is based on the molecular motions of the polar molecules and ions inside the solvent and vegetal matrix; it is strongly influenced by the dielectric constants of the solid-liquid-vapors system, developed by process evolution. This heating way realizes a more homogeneous temperature distribution at plant powder suspension level (Kosar et al., 2007; Chemat et al., 2005).

The aim of our work was to evaluate the essential oil of Foeniculum vulgare subsp. Piperitum fruits (bitter fennel), extracted by three different extraction methods viz. supercritical fluid extraction (SFE) using $\mathrm{CO}_{2}$ as extractant, microwave-assisted extraction (MAE) and the classical method, Hydro-distillation (HD), with GC/MS.

\section{Materials and methods Plant Material}

Wild bitter fennel (Foeniculum vulgare subsp. Piperitum) fruits were collected from Mediterranean Coastal Region (Matruh-El obayedd) during May 2011. The plant was identified by Prof. Dr. Kamal M. Zayed and Dr. Ibrahim Elgarf, Taxonomists, Cairo Univ., Faculty of Science, Botany Dept., Cairo, Egypt, to whom the authors are deeply indebted. The ripe fruits were ground into fine powder. A voucher specimen was kept in the herbarium of Botany Department. 
http://dx.doi.org/10.4314/ajtcam.v11i2.8

\section{Extraction Methods}

Hydrodistillation (HD)

$100 \mathrm{~g}$ of ground fruits and $1000 \mathrm{~mL}$ distilled water were placed in a $2000 \mathrm{~mL}$ round-bottom flask and connected to a Clevenger-type apparatus to extract the essential oil with hydrodistillation for $3 \mathrm{hrs}$. The resulted essential oil was collected, dried with anhydrous sodium sulfate, and kept in a dark glass bottle at $4^{\circ} \mathrm{C}$ until analyzed by GC/MS (Shahat et al. 2011; Abdelaaty et al., 2012b).

Table 1: Extractable essential oils (in \%0 through three methods

\begin{tabular}{|l|l|l|l|l|l|}
\hline $\begin{array}{c}\text { Method of } \\
\text { extraction }\end{array}$ & $\begin{array}{l}\text { Essentail oil } \\
\text { \% }\end{array}$ & Pinene & Fenchone & Limonene & Anethol \\
\hline HD & $0.98 \%$ & $3 \%$ & $22 \%$ & $3.5 \%$ & $65 \%$ \\
\hline $\mathbf{C O}_{\mathbf{2}}$ SFE & $2.2 \%$ & $0.8 \%$ & $18 \%$ & $1.2 \%$ & $72 \%$ \\
\hline MWHD & $2.8 \%$ & $1.5 \%$ & $28 \%$ & $2.2 \%$ & $55 \%$ \\
\hline
\end{tabular}

\section{Supercritical Fluid Extraction}

An Applied Separation system in the SFE mode was used for extraction. The extraction vessel was a $10 \mathrm{~mL}$ stainless steel vessel. Supercritical fluid extractions were conducted at pressures of 200 bar and temperature of $50{ }^{\circ} \mathrm{C}$ for a duration of 15 min, in static mode, followed by $3 \mathrm{hrs}$, in dynamic mode with $\mathrm{CO}_{2}$ gas flow rate $1 \mathrm{~L} / \mathrm{min}$ (Damianova et al., 2004).

\section{Microwave Extraction}

The essential oil was obtained by hydrodistillation for 60 min using a Clevenger-type apparatus placed in a modified microwave oven (MARS 240v/ 50Hz). During distillation, time, temperature, pressure and power were monitored and controlled with the "easy-control" software package of the system. Microwave power applied to the plant material was controlled by a shielded thermocouple inserted directly into the flask. The oven was operated for $10 \mathrm{~min}$ at $800 \mathrm{Watts}$ up to $1000^{\circ} \mathrm{C}$, and then kept at $1000^{\circ} \mathrm{C}$ for $50 \mathrm{~min}$ at 500 Watts followed by 5 min of ventilation. Essential oil percentages obtained from the experiments were calculated on moisture free basis. The essential oils obtained at different conditions were collected in amber colored vials, dehydrated with anhydrous sodium sulfate, capped under nitrogen, and kept at $4^{\circ} \mathrm{C}$ until being analyzed (Kosar et al., 2007; Árpád et al., 2011).

\section{Gas Chromatography/Mass Spectrometry (GC/MS)}

GC/MS analyses of the obtained essential oils were carried out using HP5890 Series II Gas Chromatograph, HP 5972 Mass Selective Detector and Agilent 6890 Series Autosampler (Agilent Technologies, USA). A supelco MDN-5S 30m by $0.25 \mathrm{~mm}$ capillary column with a 0.5 $\mu \mathrm{m}$ film thickness was used with helium as the carrier gas at a flow rate of $1.0 \mathrm{ml} / \mathrm{min}$. The GC oven temperature was programmed at an initial temperature of $40{ }^{\circ} \mathrm{C}$ for 5 minutes, then heated up to $140{ }^{\circ} \mathrm{C}$ at $5{ }^{\circ} \mathrm{C} / \mathrm{min}$ and held at $140{ }^{\circ} \mathrm{C}$ for $5 \mathrm{~min}$, then heated to $280{ }^{\circ} \mathrm{C}$ at $9{ }^{\circ} \mathrm{C} / \mathrm{min}$ and held for 5 additional minutes. Injector and detector temperatures were set at $250^{\circ} \mathrm{C}$. Mass spectrometry was run in the electron impact mode (EI) at $70 \mathrm{eV}$. The identification of the chemical constituents of the essential oil was determined by their GC retention times, interpretation of their mass spectra and confirmed by mass spectral library search using the national Institute of Standards and Technology (NIST) data- base with those of authentic samples or published mass spectral data (Adams, 2007). The quantitative data were expressed as relative percentage of the oil constituents calculated from the GC peak areas without using correction factors, and each oil was analyzed three times.

\section{Results \\ Evaluation of essential oils of different extraction techniques}

We demonstrate our results on comparison of both the yield and composition of essential oil fractions obtained by traditional hydrodistillation and the newly implemented extraction methods (Table 1). In this work, Fennel has been extracted using three different extraction techniques; hydrodistillation, supercritical fluid extraction and microwave assisted extraction. The obtained oils have been analyzed by GC/MS. The following table summarizes the obtained essential oil percentages and the relative percent of the major constituents.

\section{Discussion}

Since the bitter fennel oil has been reported to contain not less than $60 \%$ anethol and $15 \%$ fenchone and not more than $6 \%$ estragol (European Pharmacopoeia, 1/2005:824; European Pharmacopoeia, 1/2005:825; Brand, 1993; Tóth, 1967; Trenkle K 1969, 1971 and 1972), with small amounts of alpha-pinene, limonene, p-cymene, beta-pinene, beta-myrcene and of a variety of other compounds. So, the results of the present work showed that the total oil extraction yield was highest by using microwave assisted extraction followed by supercritical fluid extraction and the lowest yield was obtained by the conventional hydrodistillation. The major oil component extracted by the three methods is anethol. The results revealed that both MAE and SFE have shown to enhance the extraction efficiency of the interested components. MAE gave the highest yield of oil as well as higher percentage of Fenchone $(28 \%)$ and the relative concentration of anethol was lowest by microwave assisted extraction, despite the highest oil yield, compared with conventional HD method. Whereas, SFE gave the highest percentage of anethol (72\%) than those detected in the extract prepared by traditional method (65\%). Despite the fact that MWHD gave the higher extraction oil yield than both the traditional method and SFE, the percentage of anethol which is the most potent compound in fennel was still lower in its extract than those of the other two methods. So, further investigations should be carried out to reach the optimum conditions to get the maximum yield of of the extract. 
http://dx.doi.org/10.4314/ajtcam.v11i2.8

In conclusion, comparison of these extraction methods revealed that they extracted essential oil with similar qualitative characteristics, however slight quantitative differences. The innovative extraction techniques, SFE and MWHD, not only enhanced the extraction of essential oil but they also saved time, reduced the solvents use and produced, ecologically, green technologies.

\section{Acknowledgment}

The present study is a part of the work of the project entitled "Economically and Environmentally Friendly Innovative Techniques for Extraction and Isolation of Medicinal and Aromatic Plants (MAP) of Egypt: A Technology Transfer Proposal (Phase I)" between STDF and National Research Centre (NRC) (1/2010-present) and to whom the authors are deeply indebted.

\section{References}

1. Abdelaaty A. Shahat, Hanaa H. Ahmed, Faiza M. Hammouda and Haider Ghaleb, (2012a). "Regulation of Obesity and Lipid Disorders by Foeniculum vulgare Extracts and Plantago ovata in High-fat Diet-induced Obese Rats". Am J of Food Tech., 7: 622-632.

2. Abdelaaty A. Shahat, Faiza M. Hammouda, Khaled A. Shams and Mahmoud A. Saleh. (2012b). "Comparative Chemical Analysis of the Essential Oil of Wild and Cultivated Fennel (Foeniculum vulgare Mill)" (JEOBP) Vol. 15, No. 2.

3. Adams, R.P. (2007). Identification of Essential Oil Components by Gas Chromatography/ Mass Spectrometry, 4th Ed. Allured Publishing Co. Carol Stream, Illinois USA.

4. Árpád Kapás, Csaba D. András, Tănase Gh. Dobre, Erika Vass, Gabriella Székely, Marta Stroescu, Szabolcs Lányi, Beáta Ábrahám (2011). "The Kinetic of Essential Oil Separation From Fennel By Microwave Assisted Hydrodistillation (MWHD)" U.P.B. Sci. Bull., Series B, Vol. 73, Iss. 4, 113-120.

5. Boulos, L. (2005). In: "Flora of Egypt", volume 2, pp 174, Al-Hadara Publishing, Cairo, Egypt.

6. Brand N. (1993) "Foeniculum". In: Hansel R, Keller K, Rimpler H. Schneider G, editors. Hagers Handbuch der Pharmazeutischen Praxis, 5th ed. Volume 5: Drogen E.O. Berlin-Heidelberg-New York-London: Springer-Verlag.: 156-181.

7. Bruyas-Bertholon, V., Lachaux. A., Dubois, J.P., Fourneret. P., and Letrilliart, L. (2012). "Which treatments for infantile colics?" La Presse Médicale, 41(7-8):404-410.

8. Chemat, S., Ait-Amar, H., Lagha, A., and Esveld, D.C., (2005). "Microwave-assisted extraction kinetics of terpenes from caraway seeds", Chem Engin and Processing, vol. 44, pp. 1320-1326.

9. Cosge, B., Kiralan, M., and Gurbuz, B. (2008). "Characteristics of fatty acids and essential oil from sweet fennel (Foeniculum vulgare Mill. var. dulce) and bitter fennel fruits (F. vulgare Mill. var. vulgare) growing in turkey". Nat Prod Res; 22: 1011-1016.

10. European Pharmacopoeia, Fennel, Bitter - Foeniculi amari fructus. Council of Europe. 01/2005:0824.

11. European Pharmacopoeia, Fennel, Sweet - Foeniculi dulcis fructus. Council of Europe. 01/2005:0825

12. Kosar, M., Özek, T., Kürkçüoglu, M., and Baser, K.H.C., (2007). "Comparison of microwave-assisted hydrodistillation and hydrodistillation methods for the fruit essential oils of Foeniculum vulgare", J of Essential Oil Res., vol. 19, no.5, pp. 426-429.

13. Lawrence, B.M. (1994). "Progress in Essential Oils". Perfum Flav, 19, 31-32.

14. Lucchesi, M., Chemat, F., and Smajda, J., (2004). "Solvent-free microwave extraction of essential oil from aromatic herbs: comparison with conventional hydrodistillation", J of Chrom A, vol. 1043, no. 23, pp. 323-327.

15. Milojević, S.Ž., Stojanović, T.D., Palić, R., Lazić, M.L., and Veljković, V.B., (2008). "Kinetics of distillation of essential oil from comminuted ripe juniper (Juniperus communis L.) berries", Biochem Engin J vol. 39, no.3, pp. 547-553.

16. Mimica-Dukić, N., Kujundžić, S., Soković, M., and Couladis, M. (2003). "Essential oil composition and antifungal activity of Foeniculum vulgare Mill. Obtained by different distillation conditions. Phytotherapy Res, 17(4):368-371.

17. Pasrija Anubhuti, Singh Rahul, Katiyar Chandra Kant (2011). "Standardization of Fennel (Foeniculum vulgare), Its Oleoresin and Marketed Ayurvedic Dosage Forms" International Journal of Pharm Sci and Drug Res; 3(3): 265-269.

18. Perry, R, Hunt, K., and Ernst, E. (2011). "Nutritional supplements and other complementary medicines for infantile colic: a systematic review". Pediatrics, 127(4):720-733.

19. Raghavan, S. (2006). "Handbook of spices, seasoning and flavourings". 2nd edition. CRC Press Taylor and Franci group, Boca Raton, New York, pp. 63-64, 104-105, 107-109.

20. Damianova, S. , Stoyanova, A. , Konakchiev, A. and Djurdjev, I. (2004), "Supercritical Carbon Dioxide Extracts of Spices. 2. Fennel (Foeniculum vulgare Mill. var. dulce Mill.) J of Ess Oil Bearing Plnts", Volume 7, Issue 3, 247-249.

21. Shahat, A.A., Ibrahim, A.Y., Hendawy, S.S., Omar, E.A., Hammouda, F.M., Abdel-Rahman, F. and Saleh, M.A. (2011). "Chemical composition and biological evaluation of essential oils from three Egyptian organic cultivation fennel verities". Molecules, 16: $1366-1377$.

22. Tóth, L. (1967). "Untersuchungen fiber das ätherische Öl von Foeniculum vulgare", Planta Med; 15: 157-172.

23. Trenkle, K. (1972). "Recent studies on fennel (Foeniculum vulgare M.) 2. The volatile oil of the fruit, herbs and roots of fruit- bearing plants", Pharmazie, 27: 319-24.

24. Trenkle, K. (1971)."Recent studies in Foeniculum vulgare. Organic acids, especially phenyl carbonic acids", Planta Med, $20: 289-301$.

25. Trenkle, K. (1969). "Contents of fennel root (Foeniculum vulgare Mill.)" Pharmazie; 24: 782.

26. WHO (2005). "Global Atlas of Traditional, Complementary and Alternative Medicine", World Health Organization, Geneva. 